\title{
КАЧЕСТВЕННАЯ И КОЛИЧЕСТВЕННАЯ ХАРАКТЕРИСТИКА ОДЫШКИ У БОЛЬНЫХ ПРОГРЕССИРУЮЩИМ ФИБРОТИЧЕСКИМ ФЕНОТИПОМ ИНТЕРСТИЦИАЛЬНЫХ БОЛЕЗНЕЙ ЛЕГКИХ, АССОЦИИРОВАННЫХ С СЕРДЕЧНО-СОСУДИСТЫМИ ЗАБОЛЕВАНИЯМИ
}

МЕДВЕДЕВ АЛЕКСАНДР ВЛАДИМИРОВИЧ, канД. меД. Наук, старший научный сотрудник отДела дифференциальной диагностики туберкулеза легких и экстракорпоральных методов лечения ФГБНУ «Центральный научноисследовательский институт туберкулеза», Россия, 107564, Москва, Яузская аллея, 2, тел. +7(499)785-90-08; +7(909)691-41-54, e-mail: alexmedved_1@mail.ru АБУБИКИРОВ АНВЕР ФАТИКОВИЧ, канд. мед. наук, старший научный сотрудник отдела дифференциальной диагностики туберкулеза легких и экстракорпоральных методов лечения ФГБНУ «Центральный научноисследовательский институт туберкулеза», Россия, 107564, Москва, Яузская аллея, 2, тел. +7(499)785-90-08; +7(916)126-86-33, e-mail: abubik_1@mail.ru ЗАЙЦЕВА АННА СЕРГЕЕВНА, канд. мед. наук, старший научный сотрудник отдела дифференциальной диагностики туберкулеза и экстракорпоральных методов лечения ФГБНУ «Центральный научно-исследовательский институт туберкулеза», Россия, 107564, Москва, Яузская аллея, 2, тел. +7(499)785-90-31, e-mail: anyasyls@yandex.ru МАЗАЕВА ЛАРИСА АЛЕКСЕЕВНА, канд. МеД. наук, научный сотрудник отДела дифференциальной диагностики туберкулеза и экстракорпоральных методов лечения ФГБНУ «Центральный научно-исследовательский институт туберкулеза", 107564, Россия, Москва, Яузская аллея, 2, тел. +7(499)785-90-31, e-mail: lara.mazaeva@yandex.ru MAKAРЬЯНЦ НАTАЛЬЯ НИКОЛАEBHA, ORCID ID: 0000-0002-6390-8759; докт. мед. наук, ведущий научный сотрудник отдела дифференциальной диагностики туберкулеза и экстракорпоральных методов лечения ФГБНУ «Центральный научно-исследовательский институт туберкулеза», Россия, 107564, Москва, Яузская аллея, 2, тел. +7(499)785-91-56, e-mail: Roman4000@yandex.ru

ШМЕЛЁВ ЕВГЕНИЙ ИВАНОВИЧ, ORCID ID: 0000-0002-1908-5601; докт. меД. наук, зав. отделом дИфференциальной диагностики туберкулеза и экстракорпоральных методов лечения ФГБНУ «Центральный научно-исследовательский институт туберкулеза», Россия, 107564, Москва, Яузская аллея, 2, тел. +7(499)785-90-08, e-mail: eishmelev@mail.ru

Реферат. Цель - анализ количественных и качественных характеристик одышки у больных фибротическим фенотипом интерстициальных заболеваний легких, ассоциированных с ишемической болезнью сердца. Материал и методы. Обследовано 49 больных: 9 пациентов с идиопатическим легочным фиброзом, 25 - с хроническим вариантом гиперсенситивного пневмонита, 14 - с неспецифической интерстициальной пневмонией. Основную группу составили 25 пациентов с интерстициальными заболеваниями легких и ишемической болезнью сердца, группу сравнения - 24 больных без ишемической болезни сердца. Проанализированы клинические симптомы, результаты анкетирования, данные инструментального исследования. Результаты и их обсуждение. Больные ишемической болезнью сердца ощущали усиление одышки раньше (через 3,21 дня), чем пациенты без нее (через 7,18 дня; $p<0,05)$. При функциональном исследовании у пациентов с кардиальной патологией регистрировалось достоверное снижение дифффузионной способности легких; $p<0,05$. Наличие ишемической болезни сердца сопровождалось интенсификацией одышки по шкале Борг, сокращением дистанции, пройденной за 6 мин, большим снижением показателей пульсоксиметрии (на 7,94\% в основной группе и на 3,26\% в группе сравнения). При компьютерной томографии выраженность «матового стекла» статистически выше у больных ишемической болезнью сердца; $p<0,05$. Легочная гипертензия, изменения правых отделов сердца наблюдались у пациентов обеих групп, гипертрофия левого желудочка - только у больных основной группы. Пациенты с «изолированным» фенотипом интерстициальных заболеваний легких жаловались на тяжесть, нехватку воздуха, больные ишемической болезнью сердца - на сжатие, стеснение в груди, у больных с легочным сердцем и сердечной недостаточностью отмечена комбинация этих ощущений. Выводы. У пациентов с интерстициальными заболеваниями легких, ассоциированных с ишемической болезнью сердца, интенсификация одышки отражает прогрессирование легочного заболевания, развитие сердечной недостаточности, хронического легочного сердца. Изучение количественных и качественных характеристик диспноэ - способ уточнения генеза одышки на этапе, предшествующем специализированным инструментальным методам диагностики.

Ключевые слова: прогрессирующий фибротический фенотип интерстициальных болезней легких, количественная и качественная оценка одышки, сердечно-сосудистые заболевания.

Для ссылки: Качественная и количественная характеристика одышки у больных прогрессирующим фрибротическим френотипом интерстициальных болезней легких, ассоциированных с сердечно-сосудистыми заболеваниями / А.В. Медведев, А.Ф. Абубикиров, Л.А. Мазаева [и др.] // Вестник современной клинической медицины. - 2021. T. 14, вып. 5. - С.34-42. DOI: 10.20969/VSKM.2021.14(5).34-42.

\section{QUALITATIVE AND QUANTITATIVE FEATURES OF DYSPNEA IN PATIENTS WITH THE PROGRESSIVE FIBROTIC PHENOTYPE OF INTERSTITIAL LUNG DISEASE ASSOCIATED WITH CARDIOVASCULAR DISEASE}

MEDVEDEV ALEXANDER V., C. Med. Sci., Senior research worker of the Department of tuberculosis differential diagnosis and extracorporeal treatment of Central Tuberculosis Research Institute, Russia, 107564, Moscow, Yauzskaya alley, 2, tel. +7(499)785-90-08; +7(909)691-41-54, e-mail: alexmedved_1@mail.ru 
ABUBIKIROV ANVER F., C. Med. Sci., Senior research worker of the Department of tuberculosis differential diagnosis and extracorporeal treatment of Central Tuberculosis Research Institute, Russia, 107564, Moscow, Yauzskaya alley, 2, tel. +7(499)785-90-08; +7(916)126-86-33, e-mail: abubik_1@mail.ru

ZAITSEVA ANNA S., C. Med. Sci., Senior research worker of the Department of tuberculosis differential diagnosis and extracorporeal treatment of Central Tuberculosis Research Institute, Russia, 107564, Moscow, Yauzskaya alley, 2, tel. +7(499)785-90-31, e-mail: anyasyls@yandex.ru

MAZAEVA LARISA A., C. Med. Sci., Research worker of the Department of tuberculosis differential diagnosis and extracorporeal treatment of Central Tuberculosis Research Institute, Russia, 107564, Moscow, Yauzskaya alley, 2, tel. +7(499)785-90-31, e-mail: lara.mazaeva@yandex.ru

MAKARYANTS NATALIA N., ORCID ID: 0000-0002-6390-8759; D. Med. Sci., Leading research worker of the Department of tuberculosis differential diagnosis and extracorporeal treatment of Central Tuberculosis Research Institute, Russia, 107564, Moscow, Yauzskaya alley, 2, tel. +7(499)785-91-56, e-mail: Roman4000@yandex.ru

SHMELEV EVGENY I., ORCID ID: 0000-0002-1908-5601; D. Med. Sci., the Head of the Department of tuberculosis differential diagnosis and extracorporeal treatment of Central Tuberculosis Research Institute, Russia, 107564, Moscow, Yauzskaya alley, 2 , tel. +7(499)785-90-08, e-mail: eishmelev@mail.ru

\begin{abstract}
Aim. Analysis of quantitative and qualitative parameters of dyspnea in patients with the fibrotic phenotype of interstitial lung disease associated with coronary artery disease. Material and methods. We examined 49 patients. Among those were 9 patients with idiopathic pulmonary fibrosis, 25 patients with chronic variant of hypersensitive pneumonitis, and 14 patients with nonspecific interstitial pneumonia. The main group consisted of 25 patients with interstitial lung diseases and coronary heart disease; comparison group consisted of 24 patients without ischemic heart disease. Clinical symptoms, questionnaire results, and instrumental study data were analyzed. Results and discussion. Patients with coronary heart disease experienced increased dyspnea earlier (after 3,21 days) than patients without it (after 7,18 days; $p<0,05)$. On functional examination, a significant decrease in pulmonary diffusion capacity was recorded in cardiac patients, $p<0,05$. Presence of coronary heart disease was accompanied by intensification of dyspnea according to Borg scale, decrease of distance walked in 6 min, significant decrease in pulse oximetry indices (by 7,94\% in the main group and by $3,26 \%$ in the comparison group). On computed tomography, the severity of «frosted glass» was statistically higher in patients with coronary heart disease, $p<0,05$. Pulmonary hypertension, changes of right heart sections were observed in both groups of patients, left ventricular hypertrophy was observed only in patients of the main group. Patients with «isolated» phenotype of interstitial lung disease complained of heaviness, shortness of breath, patients with coronary heart disease complained of compression, tightness in chest, patients with pulmonary heart disease and heart failure had combination of these sensations. Conclusion. In patients with interstitial lung diseases, associated with coronary heart disease, dyspnea intensification reflects progression of lung disease, development of heart failure, and chronic pulmonary heart disease. Study of quantitative and qualitative characteristics of dyspnea is a way to specify the origin of dyspnea at the stage preceding specialized instrumental diagnostic methods.
\end{abstract}

Key words: progressive fibrotic phenotype of interstitial lung diseases, quantitative and qualitative assessment of dyspnea, cardiovascular diseases.

For reference: Medvedev AV, Abubikirov AF, Mazaeva LA, Zaitseva NN, Makaryants AS, Shmelev El. Qualitative and quantitative features of dyspnea in patients with progressive fibrotic phenotype of interstitial lung disease associated with cardiovascular disease. The Bulletin of Contemporary Clinical Medicine. 2021; 14 (5): 34-42. DOI: 10.20969/VSKM.2021.14(5).34-42.

$\mathrm{B}$ ведение. Одышка является ведущим клиническим симптомом прогрессирующего фиибротического фенотипа интерстициальных болезней легких. К этому фенотипу относятся идиопатический легочный фиброз, фрибротический френотип неспецифрической интерстициальной пневмонии, хронический гиперчувствительный пневмонит, интерстициальные заболевания легких, ассоциированные с системными заболеваниями соединительной ткани, и некоторые другие варианты интерстициальных заболеваний, для которых общими являются рентгенологический образ обычной интерстициальной пневмонии и прогрессирующее течение [1]. Наличие кардиальной патологии отмечено у $68 \%$ больных фибротическим френотипом интерстициальных заболеваний легких. Наиболее часто встречаются ишемическая болезнь сердца (43\%), артериальная гипертензия (52\%), наджелудочковые нарушения ритма $(16 \%)$, сердечная недостаточность $(14 \%)$ [2]. Сочетание фрибротического френотипа интерстициальных заболеваний легких и ишемической болезни сердца сопровождается усилением одышки, ограничением фризической активности, снижением качества жизни [3]. Причины усиления одышки у этих больных различны [4]. Наличие фриброзной трансформации легочной ткани, снижение дыхательных объемов, развитие хронического легочного сердца расценивают как «преимущественно легочные» причины одышки [5]

Прогрессирование систолической дисфункции левого желудочка при ишемической болезни сердца, развитие гиперволемии при нарушении ритма и недостаточности кровообращения составляют группу «кардиальных» причин одышки [6, 8]. Врачи общей практики часто расценивают одышку как «смешанную», не выявляя конкретных причин ее развития.

По качественному описанию нарушения дыхания («язык одышки») можно определить возможный механизм диспноэ («легочный», «сердечный», «смешанный»). Изучение количественных характеристик одышки, анкетирование пациента с анализом словесных дыхательных ощущений позволяют не только предположить первопричину появления одышки, но и разработать алгоритм рационального обследования больных прогрессирующим френотипом интерстициальных заболеваний легких, сочетанных с сердечно-сосудистыми заболеваниями. 
Цель исследования - изучение качественных и количественных характеристик одышки у больных фрибротическим френотипом интерстициальных заболеваний легких, ассоциированных с заболеваниями сердечно-сосудистой системы; сопоставление результатов анкетирования с данными функциональных и инструментальных методов обследования.

Материал и методы. В исследование включены 49 пациентов с фибротическим фенотипом интерстициальных заболеваний легких (фИЗЛ). Диагноз устанавливали по критериям диагностики интерстициальных заболеваний легких [7]. У 9 пациентов диагностировали идиопатический легочный фиброз, у 26 - хронический вариант гиперсенситивного пневмонита, у 14 - фрибротический френотип неспецифической интерстициальной пневмонии. У 25 больных была диагностирована ишемическая болезнь сердца. Наличие ишемической болезни сердца и сердечной недостаточности было подтверждено в соответствии с рекомендациями Европейского общества кардиологов (European Society of Cardiology) [9] и Американского совета диагностики и лечения сердечной недостаточности (The Heart Failure Society of America) [10]. Критериями исключения из исследования были III-IV функциональные классы хронической сердечной недостаточности, болезни соединительной ткани, онкологические заболевания, вирус иммунодефицита человека. Проведен анализ длительности легочного и кардиального заболеваний, оценка продолжительности усиления одышки за последнее время. У всех пациентов оценивали интенсивность курения, нутритивный статус с изучением ростовесовых показателей (индекс массы тела). Инструментальное исследование включало в себя эхокардиографию, компьютерную томографию органов грудной клетки, спирометрию, исследование дифффузии газов через альвеолярно-капиллярную мембрану. Интенсивность респираторных симптомов оценена по степени их выраженности (1 балл - слабая выраженность симптома, 2 балла - средняя его выраженность, 3 балла - выраженный симптом). Для трактовки рентгенологических находок компьютерной томографии использовали метод Kazerooni [11]. Для количественной оценки одышки применяли шкалу Британского медицинского исследовательского совета (Medical Research Counsil, MRC), шкалу Борга и шкалу переносимости фризической нагрузки (Clinical Resistant Pattern, CRP). Шкалу MRC использовали для интерпретации повседневной фризической нагрузки (0 баллов - нет одышки, 4 балла - одышка развивается при малейшей нагрузке). 20-балльная шкала CRP и 10-балльная шкала Борга отражали показатели переносимости физической нагрузки при проведении функциональных тестов [12]. Они оценены дважды: перед началом и по завершении 6-минутного шагового теста. Качественная характеристика одышки проведена при помощи вербального 8-кластерного опросника одышки [13]. Выраженность сердечной недостаточности, ее течение и прогноз оценивались по шкале оценки клинического состояния (ШОКС) больного сердечной недостаточностью [14]. Количественный анализ проводили с помощью статистической программы Statistica v6.0. Перед началом расчетов проводилась проверка на нормальность распределения с помощью критерия согласия Колмогорова - Смирнова и равенство дисперсий методом Ливена. При нормальном распределении выборки использовали t-критерий Стьюдента. При сравнительном анализе непараметрических данных использовали параметр Манна-Уитни. Результаты расценены как достоверные при $p<0,05$.

Результаты и их обсуждение. Обследовано 49 больных фрибротическим фенотипом интерстициальных заболеваний легких (26 мужчин, 23 женщины) в возрасте от 48,3 до 67,4 года. Проведен сравнительный анализ клинических симптомов, демографических данных, сопутствующих заболеваний, продолжительности ишемической болезни сердца и фрибротического фенотипа интерстициальных заболеваний легких у пациентов двух групп. В основную группу вошли 25 больных фрибротическим фенотипом интерстициальных заболеваний легких, ассоциированных с ишемической болезнью сердца (13 мужчин, 12 женщин, средний возраст - 58,73 года). Длительность фибротического фенотипа интерстициальных заболеваний легких составила 3,47 года, длительность ишемической болезни сердца - 4,56 года. Активными курильщиками были $5(20,0 \%)$ больных, бывшими курильщиками $3(12,0 \%)$ пациента, индекс курения в основной группе составил $(7,26 \pm 1,94)$ года (табл. 1).

Группу сравнения составили 24 пациента с фибротическим фенотипом интерстициальных заболеваний легких без ишемической болезни сердца [13 мужчин, 11 женщин, средний возраст $(56,44 \pm 7,15)$ года]. Продолжительность фрибротического фенотипа интерстициального легочного заболевания составила 3,81 года, индекс курения $(6,88 \pm 1,58)$ года. Длительность интерстициального заболевания у лиц из основной группы была меньше, чем у больных без ИБС. Интенсивность кашля у больных ишемической болезнью сердца составила 2,09 балла, одышки - 2,82 балла, выделения мокроты - 1,28 балла, что было выше, чем в группе без ишемической болезни сердца. Допустимо предположение, что наличие сердечно-сосудистого заболевания увеличивает тяжесть и скорость проявления клинических признаков интерстициальной болезни легких.

Анализ сопутствующей патологии у пациентов с фибротическим фенотипом интерстициальных заболеваний легких позволил исключить ее в качестве причин усиления одышки. Артериальная гипертензия встречалась практически с равной частотой: у $16,0 \%$ в группе больных ишемической болезнью сердца и у $16,6 \%$ в группе больных с «изолированным» фрибротическим фенотипом интерстициального заболевания легких.

Висцеральное ожирение и продолжительность табакокурения рассматривали в качестве факторов риска развития ишемической болезни сердца и одышки, связанной с этим заболеванием. Индекс курения у пациентов с ишемической болезнью был больше, чем у больных без нее, но статис- 
Характеристика больных фибротическим фенотипом интерстициальных заболеваний легких

Characteristics of patients with the fibrotic phenotype of interstitial lung disease

\begin{tabular}{|c|c|c|}
\hline Показатель & Больные фрИЗЛ с ИБС, $n=25$ & Больные фИЗЛ без ИБС, $n=24$ \\
\hline Возраст, лет & $58,73 \pm 6,21[55,4 ; 67,4]$ & $56,44 \pm 7,15[48,3 ; 59,23]$ \\
\hline Пол, м/ж & $13 / 12$ & $13 / 11$ \\
\hline Продолжительность фИЗЛ, лет & $3,47[3,23 ; 3,89]$ & $3,81[3,11 ; 4,22]$ \\
\hline Продолжительность ИБС, лет & $4,56[3,82 ; 4,69]$ & - \\
\hline Индекс курения, пачка-лет & $7,26 \pm 1,94[6,73 ; 7,75]$ & $6,88 \pm 1,58[6,42 ; 7,02]$ \\
\hline Индекс массы тела (ИМТ), кә/м² & $26,93 \pm 3,25[25,47 ; 27,31]$ & $25,63 \pm 2,84[23,73 ; 26,01]$ \\
\hline Одышка, балл & $2,76[2,42 ; 2,88]$ & $2,39[2,2182,46]$ \\
\hline Кашель, балл & $2,11[1,54 ; 2,19]$ & $1,81[1,65 ; 1,93]$ \\
\hline Выделение мокроты, балл & $1,28[1,14 ; 1,50]$ & $1,17[1,06 ; 1,23]$ \\
\hline Шкала одышки MRC, балл & $3,12[2,98 ; 3,15]$ & $2,92[2,74 ; 3,09]$ \\
\hline $\begin{array}{l}\text { АГ, абсолютное количество, } \\
\text { процентное (\%) соотношение }\end{array}$ & $4(16,0 \%)[8,01 ; 19,02]$ & $4(16,6 \%)[12,5 ; 20,83]$ \\
\hline $\begin{array}{l}\text { ХСН, абсолютное количество, \%, } \\
\text { функциональный класс (ФК) NYHA }\end{array}$ & $\begin{array}{l}6(24 \%)[16,1 ; 28,0 \%] \\
\text { NYHA II* }\end{array}$ & $3(12,5 \%)[8,33 ; 16,6 \%]$, NYHA I \\
\hline Шкала оценки ХСН ШОКС, балл & $4,18[4,13 ; 4,28]$ & $2,79[2,64 ; 2,95]$ \\
\hline Длительность усиления одышки, дней & $3,21[3,03 ; 3,84]^{*}$ & $7,18[6,94 ; 9,67]$ \\
\hline Сроки визита к врачу, дни & $5,21[5,16 ; 9,32]$ & $8,74[7,28 ; 10,54]$ \\
\hline
\end{tabular}

Примечание: 1. физЛ - фибротический фенотип интерстициальных заболеваний легких; АГ - артериальная гипертензия; ИБС - ишемическая болезнь сердца; ХСН - хроническая сердечная недостаточность; ФК NYHА - функциональная шкала оценки сердечной недостаточности Нью-Йорской кардиологической ассоциации; ШОКС - шкала оценки клинического состояния больного хронической сердечной недостаточностью; ИМТ - индекс массы тела; \% - процентное соотношение признака. 2. Данные представлены в виде медианы, первого и третьего квартилей - Me [k25\%; k75\%]. Для расчета статистической значимости различий параметров, таких как возраст, индекс курения, индекс массы тела, между группами с наличием и отсутствием ИБС использован критерий Стьюдента. 3. Для расчета статистической значимости различий по половому составу, абсолютному количеству больных, количеству больных артериальной гипертензией, количеству случаев сердечной недостаточности использован двусторонний точный критерий Фишера. 4. Для расчета статистической значимости различий по другим показателям в анализируемых подгруппах использован двусторонний U-критерий Манна - Уитни. *5. Отличие от подгруппы фИЗЛ без ИБС статистически значимо $(p<0,05)$.

тически значимого различия показателей между сравниваемыми группами не отмечено. У больных ишемической болезнью сердца и ожирением развивался дефицит мышечной массы, возрастала потребность миокарда в кислороде, что, наряду с уменьшением легочных объемов, провоцировало усиление одышки [15]. При изучении питательного статуса исследуемых больных не было отмечено повышения индекса массы тела, что исключало ожирение как причину появления одышки. У пациентов с постинфарктным кардиосклерозом одышка может быть единственным клиническим проявлением сердечной недостаточности. У больных фрибротическим фенотипом интерстициального заболевания легких статистически значимо чаще встречалась сердечная недостаточность (в 24\% случаев), в отличие от больных без ишемической болезни сердца (в $12,5 \%$ случаев); $p<0,05$. При развитии хронической сердечной недостаточности пациенты уменьшали свою активность, приспосабливаясь к одышке. Об адаптации к физической нагрузке свидетельствовало отсутствие статистически значимых различий одышки по шкале MRC у пациентов обеих групп. Клинические признаки хронической сердечной недостаточности имеют низкую специфичность, поскольку субъективные ощущения больного не всегда соответствуют стадиям сердечной недостаточности. Для количественного определения тяжести симптомов сердечной недостаточностью использовали шОКС $[15,16]$.
У больных ишемической болезнью сердца наблюдали большую выраженность клинических симптомов (кашля, одышки) и высокую степень сердечной недостаточности, выявленные с помощью ШОКС (4,18 балла); II функциональный класс был присвоен в соответствии с классификацией NYHA. B группе пациентов без ишемической болезни сердца интенсивность клинических симптомов была ниже, признаки сердечной недостаточности были выражены в меньшей степени: ШОКС - 2,79 балла, что соответствовало I функциональному классу по NYHA. При сопоставлении времени появления одышки со сроками визита к врачу было установлено, что больные фибротическим фенотипом интерстициального заболевания легких и ишемической болезнью сердца ощущают усиление одышки раньше (в среднем через 3,21 дня), чем пациенты с «изолированным» фрибротическим френотипом интерстициального легочного заболевания (через 7,18 дня); $p<0,05$.

Большая интенсивность одышки у больных основной группы, ее усиление в более ранние сроки предполагали своевременное обращение к врачу. Однако более половины пациентов с ишемической болезнью сердца (14 больных, 56,0\%) и большинство больных без ишемической болезни сердца (16 пациентов, 66,7\%) не связывали усиление одышки с прогрессированием кардиального или легочного заболеваний, а объясняли это длительным стажем табакокурения. Вероятно, поэтому пациенты обеих групп не сразу обращались к врачу после появления 
одышки: больные ишемической болезнью сердца - через 5,21 дня после усиления «привычной» одышки; больные без ишемической болезни сердца - через 8,74 дня. Только выраженное ограничение повседневной двигательной активности, развитие приступов стенокардии и перебоев в работе сердца, появление видимых признаков сердечной недостаточности (цианоз губ, отечный синдром) заставляли больных обратиться к врачу для уточнения причин усиления одышки.

Пациентам с ишемической болезнью сердца проводили специализированное инструментальное обследование, результаты обследования сопоставляли с клинической симптоматикой. Эти данные представлены в табл. 2.

При анализе спирометрии и бодиплетизмографрии у больных фрибротическим фенотипом интерстициального заболевания выявлено уменьшение общей емкости легких и остаточного легочного объема за счет снижения жизненной емкости легких. Уменьшение этих показателей более существенно в группе пациентов с ишемической болезнью сердца и отражает снижение растяжимости легочной ткани. Уменьшение эластической тяги легких развивалось вследствие фиброзной трансформации легочной ткани, ретикулярных изменений, формирования тракционных бронхоэктазов, субплевральных кистозных образований. В группе больных фибротическим френотипом интерстициального заболевания легких с ишемической болезнью сердца уменьшение жизненной емкости легких, проходимости воздушного потока на уровне крупных бронхов было связано с отеком периваскулярного интерстиция, повышением васкуляризации интерстициальной ткани при гиперволемии, приводящими к большему снижению дыхательных объемов.

У больных постинфарктным кардиосклерозом, сердечной недостаточностью снижение мгновенного объема фрорсированного выдоха, пиковой скорости выдоха связано с развитием систолической дисфункции левых отделов сердца; уменьшение $\mathrm{MCB}_{25}$ объяснялось отеком мелких бронхов и снижением их проходимости.

Таблица 2

Результаты обследования больных фибротическим фенотипом интерстициального заболевания легких при наличии или отсутствии ИБС

Table 2

Results of examination of patients with fibrotic phenotype of interstitial lung disease in the absence of CHD

\begin{tabular}{|c|c|c|}
\hline Показатель & $\begin{array}{c}\text { Больные фИЗЛ с ИБС, } \\
n=25\end{array}$ & $\begin{array}{l}\text { Больные фИЗЛ без ИБС, } \\
n=24\end{array}$ \\
\hline ЖЕЛ, \% & $53,6 \pm 2,9[51,82 ; 56,51]$ & $61,8 \pm 3,6[57,93 ; 64,66]$ \\
\hline $\mathrm{OФB}_{1}, \%$ & $40,8 \pm 4,2[37,43 ; 45,58]^{*}$ & $53,4 \pm 2,3[51,32 ; 55,81]$ \\
\hline ПСВ, $\%$ & $37,7 \pm 3,8[33,22 ; 40,11]^{*}$ & $56,4 \pm 6,3[47,62 ; 59,06]$ \\
\hline $\mathrm{MCB}_{75}, \%$ & $48,9 \pm 4,8[44,13 ; 51,32]$ & $54,94 \pm 7,2[50,22 ; 58,14]$ \\
\hline $\mathrm{MCB}_{25}, \%$ & $17,6 \pm 4,7[15,83 ; 19,63]$ & $28,8 \pm 6,9[27,28 ; 32,53]$ \\
\hline ООЛ, \% & $68,52[67,15 ; 71,32]$ & $66,43[62,12 ; 68,08]$ \\
\hline ОЕЛ, \% & $64,31[63,02 ; 67,93]$ & $62,55[58,94 ; 64,17]$ \\
\hline DLCO, моль/мин/к Рa & $42,93 \pm 6,4[35,1 ; 48,6]^{*}$ & $55,16 \pm 2,1[47,23 ; 58,01]$ \\
\hline $\mathrm{PaO}_{2}$, мM pm.cm. & $68,99 \pm 5,4[67,7 ; 72,5]$ & $70,84 \pm 3,7[68,52 ; 72,65]$ \\
\hline $\mathrm{PaCO}_{2}$, мм pm.cm. & $38,26 \pm 3,9[36,1 ; 41,7]$ & $37,84 \pm 2,9[37,06 ; 39,98]$ \\
\hline ТКИМ, мм & $1,162[0,84 ; 1,179]^{*}$ & $0,949[0,892 ; 0,970]$ \\
\hline 6-MT, $M$ & $291,6 \pm 9,2[254,315,1]^{*}$ & $379,5 \pm 4,4[342,2 ; 413,5]$ \\
\hline Шкала Борга в покое, балл & $1,29[0,99 ; 1,42]^{*}$ & $0,51[0,47 ; 0,74]$ \\
\hline Шкала Борга после 6 MT & $4,11[3,52 ; 4,58]$ & $3,59[3,23 ; 3,88]$ \\
\hline Шкала CRP, балл & $6,68[6,18 ; 7,24]$ & $5,52[5,31 ; 5,69]$ \\
\hline$\Delta \mathrm{SpO}_{2}, \%$ & $7,94[7,31 ; 8,15]$ & $3,26[3,02 ; 3,95]$ \\
\hline Интерстициальные изменения на КТ, балл & $2,19[2,11 ; 2,38]^{*}$ & $1,58[1,39 ; 1,87]$ \\
\hline Ретикулярные изменения на КТ, балл & $2,65[2,42 ; 3,12]$ & $2,41[2,05 ; 2,63]$ \\
\hline Р сист. ЛА, мм рт.ст. & $33,89 \pm 4,6[33,07 ; 34,52]$ & $32,11 \pm 3,82[30,67 ; 32,98]$ \\
\hline ТСПЖ, см & $0,619[0,52 ; 0,634]^{*}$ & $0,558[0,489 ; 0,608]$ \\
\hline ТМЖП, см & $1,136 \pm 0,12[1,09 ; 1,158]^{*}$ & $0,891 \pm 0,11[0,856 ; 1,052]$ \\
\hline ТЗЛЖ, см & $1,128 \pm 0,13[0,972 ; 1,164]$ & $1,023 \pm 0,12[0,942 ; 1,158]$ \\
\hline
\end{tabular}

Примечание: 1. ЖЕЛ - жизненная емкость легких, \% от должных величин; ОФВ - объем форсированного выдоха за 1-ю секунду (мгновенный объем форсированного выдоха); MCВ $_{75}$ - мгновенная скорость воздушного потока при форсированном выдохе $75 \%$ ЖЕЛ от начала выдоха; MCВ $_{25}$ - мгновенная скорость воздушного потока при форсированном выдохе $25 \%$ ЖЕЛ; DLCO - диффузионная способность легких по оксиду углерода, выполненная методом одиночного выдоха; ОЕЛ - общая емкость легких; ООЛ - остаточный объем легких; $\mathrm{PaO}_{2}$ - напряжение кислорода капиллярной крови; $\mathrm{PaCO}_{2}$ - напряжение углекислого газа капиллярной крови; ТКИМ - толщина комплекса интима-медиа; 6-MT - 6-минутный шаговый тест; $\Delta \mathrm{SpO}_{2}-$ изменение сатурации крови по показателям пульсоксиметрии; Р сист. ЛА - систолическое давление легочной артерии; ТСПж - толщина стенки правого желудочка; ТМЖП - толщина межжелудочковой перегородки; ТЗЛЖ - толщина задней стенки левого желудочка. 2. Для расчета статистической значимости различий параметров ЖЕЛ, ОФВ, , ПСВ, $\mathrm{MCB}_{75}, \mathrm{MCB}_{25}, \mathrm{PaO}_{2}, \mathrm{PaCO}_{2}$, ТМЖП, Р сист. ЛА, ТЗЛЖ между группами с наличием и отсутствием ишемической болезни сердца использован критерий Стьюдента. 3. Для расчета других показателей в анализируемых подгруппах использован двусторонний U-критерий Манна - Уитни. *4. Отличие от подгруппы фиЗЛ без ИБС статистически значимо $(p<0,05)$. 
При анализе дифффузионной способности легких регистрировалось достоверное уменьшение показателей DLCO у больных фрибротическим френотипом интерстициальных заболеваний легких, ассоциированных с ишемической болезнью сердца $(p<0,05)$. По-видимому, снижение диффрузионной способности легких обусловлено морфологическими изменениями легочной ткани: инфильтрацией и фиброзированием вазального интерстиция, приводящими к сокращению площади газообмена; а также к атеросклеротическим поражениям сосудистой стенки со снижением дифффузии газов. О структурных изменениях микроциркуляторного русла, повышении жесткости артериол альвеолярно-капиллярной мембраны косвенно свидетельствует увеличение толщины комплекса интима-медиа. Анализ показателей парциального давления кислорода и углекислого газа в крови отражает развитие гипоксемии и гиперкапнии у больных обеих групп. Большую выраженность показателей наблюдали у пациентов с фрибротическим фенотипом интерстициальных заболеваний легких, сочетанных с ишемической болезнью сердца, статистические различия между группами отсутствовали.

Для оценки функционального статуса всем больным был проведен тест 6-минутной ходьбы. Меньшее расстояние, пройденное за 6 мин, большие значения одышки на шкалах Борга и CRP, выраженная десатурация (достоверное изменение сатурации крови по итогам тестирования - 7,94\% в основной группе и 3,26\% в группе сравнения; $p<0,05)$ свидетельствовали о статистически значимом снижении толерантности к физической нагрузке у больных фИЗЛ при наличии ишемической болезни сердца. Результаты тестирования отражали отягощающее влияние интерстициального и кардиального заболеваний друг на друга: ишемическая болезнь у больного интерстициальным заболеванием легких являлась фрактором, препятствовавшим преодолению расстояния во время теста; наличие фИЗЛ снижает функциональный статус пациента с ишемической болезнью сердца.

Выявленные рентгенологические изменения компьютерной томографии органов грудной клеткти были условно разделены на две группы. Фиброзная трансформация кортикальных и базальных отделов легких, утолщение стенок бронхов, уплотнение межальвеолярных перегородок, нарушение архитектоники легких с развитием «сотового легкого» расценивали как ретикулярные изменения. Участки инфильтрации септального и внутридолькового интерстиция, заполнение альвеол транссудатом при повышении объема капиллярного кровотока расценивали как интерстициальные изменения.

Статистически значимого различия интенсивности ретикулярных изменений у анализируемых больных не выявлено. Выраженность интерстициальных изменений выше у пациентов основной группы $(p<0,05)$.

У больных с «изолированным» фенотипом этот симптом отражал изменения интерстиция и являлся проявлением только легочного заболевания. У больных ишемической болезнью сердца он был обусловлен альвеолитом, отечным пропитыванием межуточной ткани вследствие гиперволемии и являлся отражением интерстициального и кардиального заболеваний.

При анализе эхокардиографии выявлено повышение систолического давления в легочной артерии и утолщение стенки правого желудочка. Отмечено, что степень легочной гипертензии и гипертрофия правого желудочка коррелируют с уровнем гипоксемии и гиперкапнии, являются показателем выраженности паренхиматозного легочного фиброза и могут свидетельствовать о прогрессировании фибротического френотипа интерстициального заболевания легких [16]. Количественная оценка структур сердца регистрировала развитие гипертрофии левого желудочка у пяти больных интерстициальным заболеванием легких с постинфрарктным кардиосклерозом (20\%). У них отмечали утолщение межжелудочковой перегородки и задней стенки левого желудочка. У остальных пациентов с ишемической болезнью сердца и у больных группы сравнения изменения геометрии левых отделов не отмечено. Высокий уровень легочной гипертензии и большие структурные изменения сердца у больных основной группы свидетельствуют о негативном влиянии ишемической болезни сердца на течение фибротического фенотипа интерстициального заболевания легких.

При анализе качественной характеристики одышки больных фиЗЛ выявлено различие ее интерпретации в зависимости от наличия или отсутствия сердечно-сосудистых заболеваний. Больные с «изолированным» фенотипом интерстициального легочного заболевания подчеркивали фразы, свидетельствующие о наличии «тяжести в груди», усиление диспноэ при движении, появление «хрипов в грудной клетке». Подобные ощущения отмечали более половины больных (54,2\%).

Все пациенты с фИЗЛ и артериальной гипертензией при описании своей одышки отражали невозможность адекватного дыхательного маневра, трудности выполнения полноценного вдоха. Большинство больных ишемической болезнью сердца и интерстициальным заболеванием легких $(72,0 \%)$ ощущали стеснение и давление в груди, усиливающиеся при фризической нагрузке. Пациенты с легочным сердцем обращали внимание на удушье и чувство страха от возможной остановки дыхания.

Bce пациенты с фрибротическим френотипом интерстициальных заболеваний легких и сердечной недостаточностью регистрировали необходимость «дополнительного физического усилия, чтобы дышать», «усиленной работы дыхательных мышц», требующейся для устранения дискомфорта дыхания. Больные основной группы при описании одышки использовали в среднем $(7,8 \pm 0,32)$ фрраз, больные фиЗЛ и артериальной гипертензией - $(8,2 \pm 0,45)$ фраз, больные только ИБС $(9,6 \pm 0,73)$ фраз, интерстициальной болезнью и хроническим легочным сердцем - $(10,3 \pm 0,42)$ фраз, пациенты с фибротическим фенотипом интерстициального заболевания легких и хронической сердечной недостаточностью - $(12,8 \pm 0,66)$ фраз. Большая интенсивность одышки, большее число 
фрраз, используемых для оценки своих дыхательных ощущений, свидетельствовали о негативном влиянии кардиальных заболеваний в развитии одышки.

Раннее анкетирование с анализом вербальных характеристик диспноэ позволило предположить возможный механизм появления одышки у больных с разными сердечно-сосудистыми заболеваниями. У пациентов с «изолированным» фенотипом интерстициального заболевания легких одышка обусловлена уменьшением легочных объемов, снижением эластических свойств легких, приводящие к усилению мышечной нагрузки. В результате возросшего мышечного напряжения появляется тяжесть в грудной клетке.

Ощущение нехватки воздуха, тяжести в груди, необходимость дополнительного физического усилия наблюдаются при прогрессировании фииротического фенотипа интерстициального заболевания легких [17]. «Язык одышки» у больных отражает выраженность рестриктивных нарушений вентиляции и способен предоставить информацию, свидетельствующую о тяжести заболевания, опытному клиницисту.

У больных ишемической болезнью сердца развивается чувство нехватки воздуха. Наблюдается дисбаланс между вдохом, эфферентной активацией дыхательного центра в ответ на тахипноэ и обратной реакцией аффферентных рецепторов дыхательной системы. Этот дисбаланс возрастает во время ангинозного приступа, вызывая сжатие и чувство тяжести в грудной клетке [18].

Усиление одышки у пациентов с гипертонической болезнью и у пациентов с легочным сердцем может быть связано с повышенной активацией центральных механизмов регуляции дыхания: стимуляцией хеморецепторов каротидного тела, механорецепторов правого предсердия и правого желудочка, барорецепторов артериальной стенки и легочной артерии [19].

У пациентов с артериальной гипертензией появлялось ощущение поверхностного, неглубокого дыхания; пациенты с легочным сердцем жаловались на удушье, чувство тяжести в грудной клетке. В случаях хронической сердечной недостаточности и гиперволемии возможно развитие функциональной гиповентиляции нижних отделов легких. Несоответствие объема вентиляции возросшему кровотоку сопровождается увеличением частоты дыхания. Способствует усилению одышки скопление жидкости в плевральной полости, затрудняющей экскурсию грудной клетки [20]. Снижение растяжимости легких, повышение внутриплеврального давления сопровождаются усиленной работой дыхательных мышц. Больные фИЗЛ и сердечной недостаточностью отмечали удушье, нехватку воздуха, тяжесть в грудной клетке, дыхательный дискомфорт, связанный с возрастанием мышечного усилия. У больных c «изолированным» фенотипом интерстициального легочного заболевания восприятие этого усилия зависело от степени снижения диффузионной способности легких и выраженности гипоксемии.

У пациентов с фИЗЛ, ассоциированных с сердечной-сосудистыми заболеваниями, оно может быть объяснено гемодинамическими причинами. В случае постинфарктного кардиосклероза, систолической диссункции левого желудочка развивается «кардиомиопатия перегрузки» (перегрузка объемом); в случае артериальной гипертензии - перегрузка давлением.

У больных с легочным сердцем повышение давления в легочных сосудах сопровождается легочной гипертензией, гипертрофией правых отделов сердца с интенсификацией одышки и необходимостью большего дыхательного усилия для ее преодоления [21].

Систематизация ощущения одышки по кластерам демонстрирует, что для больных с «изолированным» фрибротическим фенотипом интерстициального заболевания легких наиболее характерны тяжесть, нехватка воздуха; для больных артериальной гипертензией - ощущение неглубокого дыхания; у больных ишемической болезнью сердца превалировало сжатие, стеснение в груди. Больных с легочным сердцем беспокоили чувство остановки дыхания, ощущение развивающегося удушья. Пациенты с хронической сердечной недостаточностью чаще всего предъявляли жалобы на тяжесть, утомление мышц, желание большего объема вдоха при дыхании. Изучение вербальных параметров одышки позволяет предположить, какие заболевания в большей мере провоцируют развитие диспноэ.

Выводы. У больных фрибротическим френотипом интерстициальных заболеваний легких наблюдаются различные сердечно-сосудистые заболевания, сопровождающиеся развитием диспноэ. Изучение количественных и качественных характеристик одышки может быть инструментом диагностики этих заболеваний. Анкетирование больных с оценкой словесных характеристик дыхательных ощущений позволяет предположить возможный механизм возникновения диспноэ. Это простой, удобный, доступный способ априорного анализа одышки на этапе, предшествующем специализированным инструментальным методам диагностики.

Прозрачность исследования. Исследование не имело спонсорской поддержки. Авторы несут полную ответственность за предоставление окончательной версии рукописи в печать.

Декларация о финансовых и других взачмоотношениях. Исследование проводилось в рамках выполнения научной темы № 0515-2019-0014 «Совершенствование методов лечения гранулематозных, интерстициальных, неспецифических заболеваний легких», утвержденной ученым советом ФГБНУ "Центральный научно-исследовательский институт туберкулеза», г. Москва. Все авторы принимали участие в разработке концепции, дизайна исследования и в написании рукописи. Окончательная версия рукописи была одобрена всеми авторами. Авторы не получали гонорар за исследование.

\section{ЛИТЕРАТУРА}

1. Potential of nintedanib in treatment of progressive fibrosing interstitial lung diseases / L. Wollin, J.H.W. Distler, E.F. Redente [et al.] // Eur. Respir J. - 2019. - Vol. 54 (3). P.1900161. - DOI: 10.1183/13993003.00161-2019. 
2. Progressive fibrosing interstitial lungdisease: clinical uncertainties, consensus recommendations, and research priorities / P.M. George, P. Spagnolo, M. Kreuter [et al.] // Lancet Respir. Med. - 2020. - Vol. 8 (9). - P.925-934. DOI: 10.1016/S2213-2600(20)30355-6. PMID: 32890499.

3. Progression of fibrosing interstitial lung disease / A.W. Wong, C.J. Ryerson, S.A. Guler // Respir. Res. 2020. - Vol. 21 (1). - P.32. - DOI: 10.1186/s12931-0201296-3.PMID: 31996266.

4. Mechanisms of progressive fibrosis in connective tissue disease (CTD) - associated interstitial lung diseases (ILDs) / P. Spagnolo, O. Distler, C.J. Ryerson // Ann. Rheum. Dis. - 2021. - Vol. 80 (2). - P.143-150. - DOI: 10.1136/annrheumdis-2020-217230. Epub. 2020 Oct. 9. PMID: 33037004.

5. Management of Fibrosing Interstitial Lung Diseases / T.M. Maher, W.J. Wuyts [et al.] // Adv. Ther. - 2019. Vol. 36 (7). - P.1518-1531. - DOI: 10.1007/s12325-01900992-9. 2019 May 22. PMID: 31119691.

6. The natural history of progressive fibrosing interstitial lung diseases / M. Kolb, F. Vašáková [et al.] // M. Respir Res. - 2019. - Vol. 20 (1). - P.57. - DOI: 10.1186/s12931 019-1022-1. PMID: 30871560

7. Progressive fibrosing interstitial lung disease: a clinical cohort (the PROGRESS study) / M. Nasser, S. Larrieu, S. Si-Mohamed [et al.] // Eur. Respir J. - 2021. Vol. 57 (2). - P.2002718. - DOI: 10.1183/13993003.027182020.

8. Wong, N.D. Epidemiological studies of $\mathrm{CHD}$ and the evolution of preventive cardiology / N.D. Wong // Nat. Rev. Cardiol. - 2014. - Vol. 11 (5). - P.276-289. - DOI: 10.1038/nrcardio.2014.26.

9. Lifestyle and impact on cardiovascular risk factor control in coronary patients across 27 countries: Results from the European Society of Cardiology ESC-EORP EUROASPIRE V. registry / K. Kotseva, G. De Backer, D. De Bacquer [et al.] // Eur. J. Prev. Cardiol. - 2019. - Vol. 26 (8). P.824-835. - DOI: 10.1177/2047487318825350.

10. Chronic heart failure - new insights / S. Ewen, A. Nikolovska, I. Zivanovic [et al.] // Chronic heart failure - new insights. - 2016. - Vol. 141 (21). - P.1560-1564. - DOI: 10.1055/s-0042-102706

11. Chest computed tomography imaging improves potential lung donor assessment / J.M. Gauthier, A.J. Bierhals, J. Liu [et al.] // J. Thorac. Cardiovasc. Surg. - 2019. Vol. 157 (4). - P.1711-1718. - DOI: 10.1016/j. jtcvs.2018.11.038.

12. Wahls, S.A. Causes and evaluation of chronic dyspnea / S.A. Wahls // Am. Fam. Physician. - 2005. - Vol. 71 (8). P.1529-1537.

13. Оценка распостраненности респираторных симптомов и возможности скрининга спирометрии в диагностике легочных заболеваний / А.Г. Чучалин, Н.Г. Халтаев, С.Н. Котляров [и др.] // Пульмонология. - 2010. - № 2. C.56-61.

14. Применение телеметрии у больных с хронической сердечной недостаточностью / Ю.В. Мареев, А.О. Зинченко, Р.П. Мясников [и др.] // Кардиология. - 2019. T. 59 (9S). - C.4-15. - DOl.org/10.18087/cardio.n530.

15. Obesity hypoventilation syndrome / J.F. Masa, J.L. Pépin, J.C. Borel [et al.] // Eur. Respir. Rev. - 2019. Vol. 28 (151). - P.180097.

16. Nathan, S.D. Treatment of pulmonary hypertension in idiopathic pulmonary fibrosis: shortfall in efficacy or trial design? / S.D. Nathan, C.S. King // Drug. Des. Devel.
Ther. - 2014. - Vol. 8. - P.875-885. - DOI: 0.2147/DDDT. S64907. eCollection 2014.

17. Lamb, Y.N. Nintedanib / Y.N. Lamb // Fibrotic Interstitial Lung Diseases. Drugs. - 2021. - Vol. 81 (5). - P.575586. - DOI: 10.1007/s40265-021-01487-0. Epub. 2021 Mar 25.

18. Niedermeyer, J. Dyspnea in airway and pulmonary diseases / J. Niedermeyer. // Internist (Berl). - 2015. Vol. 56 (8). - P.882-889. - DOI: 10.1007/s00108-0153692-1.

19. Wahls, S.A. Causes and evaluation of chronic dyspnea / S.A. Wahls // Am. Fam Physician. - 2012. - Vol. 86 (2). P.173-182.

20. Dyspnea. Profile of the most important diagnostic tests / $\mathrm{N}$. Abolmaali, H. Foelske, H. Magnussen [et al.] // Internist (Berl). - 2015. - Vol. 56 (8). - P.872-881. - DOI: 10.1007/ s00108-015-3687-y.

21. Ewert, R. Dyspnea. From the concept up to diagnostics / R. Ewert, S. Gläser// Internist (Berl). - 2015. - Vol. 56 (8). P.865-871. - DOI: 10.1007/s00108-015-3690-3.

\section{REFERENCES}

1. Lutz Wollin , Jörg H W Distler, Elizabeth F Redente, David W H Riches, Susanne Stowasser, Rozsa SchlenkerHerceg, Toby M Maher, Martin Kolb. Potential of nintedanib in treatment of progressive fibrosing interstitial lung diseases. Eur Respir J. 2019; 54 (3): 1900161. DOI: 10.1183/13993003.00161-2019.

2. George PM, Spagnolo P, Kreuter M, Altinisik G, Bonifazi M, Martinez FJ, Molyneaux PL, Renzoni EA, Richeldi L, Tomassetti S, Valenzuela C, Vancheri C, Varone F, Cottin V, Costabel U. Progressive fibrosing interstitial lungdisease: clinical uncertainties, consensus recommendations, and research priorities. Lancet Respir Med. 2020; 8 (9): 925934. DOI: 10.1016/S2213-2600(20)30355-6

3. Wong AW, Ryerson CJ, Guler SA. Progression of fibrosing interstitial lung disease. Respir Res. 2020; 21 (1): 32. DOI: 10.1186/s12931-020-1296-3.

4. Spagnolo P, Distler O, Ryerson CJ, Tzouvelekis A, Lee JS, Bonella F, Bouros D, Hoffmann - Vold AM, Crestani B, Matteson EL. Mechanisms of progressive fibrosis in connective tissue disease (CTD) - associated interstitial lung diseases (ILDs). Ann Rheum Dis. 2021; 80 (2): 143-150. DOI: 10.1136/annrheumdis-2020-217230

5. Maher TM, Wuyts WJ, et al. Management of Fibrosing Interstitial Lung Diseases. Adv Ther. 2019; 36 (7): 15181531. DOI: 10.1007/s12325-019-00992-9

6. Kolb $M$, Vašáková $F$, et al. The natural history of progressive fibrosing interstitial lung diseases. M. Respir Res. 2019; 20 (1): 57. DOI: 10.1186/s12931019-1022-1

7. Nasser M, Larrieu S, Si-Mohamed S, Ahmad K, Boussel L, Brevet M, Chalabreysse L, Fabre C, Marque S, Revel D, Thivolet-Bejui F, Traclet J, Zeghmar S, MaucortBoulch D, Cottin V, Nasser M, et al. Progressive fibrosing interstitial lung disease: a clinical cohort (the PROGRESS study). Eur Respir J. 2021; 57 (2): 2002718. DOI: 10.1183/13993003.02718-2020

8. Nathan D Wong. Epidemiological studies of CHD and the evolution of preventive cardiology. Nat Rev Cardiol. 2014; 11 (5): 276-289. DOI: 10.1038/nrcardio.2014.26

9. Kotseva K, De Backer G, De Bacquer D, Rydén L, Hoes A, Grobbee D, et al. Lifestyle and impact on cardiovascular risk factor control in coronary patients across 27 countries: 
Results from the European Society of Cardiology ESCEORP EUROASPIRE V registry. Eur J Prev Cardiol. 2019; 26 (8): 824-835. DOI: 10.1177/2047487318825350

10. Sebastian Ewen, Alexandra Nikolovska, Ina Zivanovic, Ingrid Kindermann, Michael Böhm. Chronic heart failure new insights. Chronic heart failure - new insights. 2016; 141 (21): 1560-1564. DOI: 10.1055/s-0042-102706

11. Gauthier JM, Bierhals AJ, Liu J, Balsara KR, Frederiksen C, Gremminger E, et al. Chest computed tomography imaging improves potential lung donor assessment. J Thorac Cardiovasc Surg. 2019; 157 (4): 1711-1718. DOI: 10.1016/j.jtcvs.2018.11.038

12. Steven A Wahls. Causes and evaluation of chronic dyspnea. Am Fam Physician. 2005; 71 (8): 1529-1537.

13. Chuchalin AG, Khaltaev NG, Kotlyarov SN, et al. Otsenka raspostranennosti respiratornykh simptomov i vozmozhnosti skrininga spirometrii $v$ diagnostike legochnykh zabolevaniy [Assessment of the prevalence of respiratory symptoms and the possibility of screening spirometry in the diagnosis of pulmonary diseases]. Pul'monologiya [Pulmonology]. 2010; 2: 56-61.

14. Mareev YuV, Zinchenko AO, Myasnikov RP, Vakhovskaya TV, Andrenko EYu, Boytsov SA, Drapkina OM. Primeneniye telemetrii u bol'nykh s khronicheskoy serdechnoy nedostatochnost'yu [The use of telemetry in patients with chronic heart failure]. Kardiologiya
[Cardiology]. 2019; 59 (9S): 4-15. DOI: 10.18087/cardio. n530

15. Masa JF, Pépin JL, Borel JC, Mokhlesi B, Murphy PB, Sánchez-Quiroga MÁ. Masa JF, et al. Obesity hypoventilation syndrome. Eur Respir Rev. 2019 Mar 14; 28 (151): 180097.

16. Steven D Nathan, Christopher S King. Treatment of pulmonary hypertension in idiopathic pulmonary fibrosis: shortfall in efficacy or trial design? Drug Des Devel Ther. 2014; 2 (8): 875 - 885. DOI: 0.2147/DDDT.S64907

17. Yvette N Lamb. Nintedanib: A Review in Fibrotic Interstitial Lung Diseases. Drugs. 2021; 81 (5): 575 - 586. DOI: 10.1007/s40265-021-01487-0

18. Niedermeyer J. Dyspnea in airway and pulmonary diseases. Internist (Berl). 2015; 56 (8): 882-889. DOI: 10.1007/s00108-015-3692-1

19. Steven A Wahls. Causes and evaluation of chronic dyspnea. Am. Fam Physician. 2012; 86 (2): 173-182.

20. Abolmaali N, Foelske H, Magnussen H, Palisch H, Schellong SM. Dyspnea. Profile of the most important diagnostic tests. Internist (Berl). 2015; 56 (8): 872-881. DOI: 10.1007/s00108-015-3687-y.

21. Ewert R, Gläser S. Dyspnea; From the concept up to diagnostics. Internist (Berl). 2015; 56 (8): 865-871. DOI: 10.1007/s00108-015-3690-3 